\title{
Becoming Urban
}

\author{
RUBina RAJA
}

Becoming urban has been recognized as one of the great turning points in human history. Urbanism afforded means of sustainability on a completely different scale than earlier and made a wide range and variety of networks possible, which could not have been sustained without the accommodating features of urbanism. However, what does it truly mean when a site is termed 'urban'? And, while so many theories have evolved around it over the last century, is this at all a helpful term? Might there be more useful terms or definitions for what really is an umbrella-term branching geographically and chronologically wide? These questions are central to the case studybased review article by Bisserka Gaydarska. I here just comment upon a few of her useful and provocative considerations and allow myself to bring some new perspectives to the reader's attention.

Clearly urbanism and what it really means when we term a site 'urban' is one of the ongoing and heated debates within archaeological research. The term 'urban' needs to be seen within a shifting research perspective as well as - often forgotten in scholarship - a historiographical perspective. Research focuses shift according to trends and angles of various kinds. A historiographical perspective tells us a lot about how focus has shifted over centuries and how archaeological and historical disciplines have turned to and picked up trends from other disciplines or at various times been a frontrunner. Bisserka Gaydarska combines these perspectives nicely in her piece and I recommend scholars and students of urban archaeology of turn to her article as an informative and critical piece of work, which is based upon solid knowledge. The article itself is a wonderful overview of scholarship concerning the urban - with an emphasis on the theoretical approaches and directions over time - their strengths and weaknesses. If I may just note one peculiar lacuna, it is odd that there is no mention of the very important research initiative headed by Mogens Herman Hansen at Copenhagen University, the so-called Polis Centre. Nonetheless the overview of the relevant literature remains faultless otherwise.

In the introduction to her article Bisserka Gaydarska states that after years of work she is still not able to tell whether the ' 236 ha fourthmillennium BC Trypillian site of Nebelivka in the Ukraine' was urban or not. This is a relevant question. However, perhaps one needs to begin at a completely different point and ask 'what makes a site urban at all?' or 'are there different sorts of urbanness?'. Such questions would allow us to look at urbanity in a different and more diverse - although not less complex - perspective. However, this does not diminish the work of Bisserka Gaydarska. It takes time and cleverness to say anything new about urbanism and she does so.

As the author very neatly sketches out there is currently a range of theories, which all offer nice bundles of criteria through which we may, by ticking the boxes, conclude whether or not a site was urban, decide on the limit to being urban or not urban. However, as she also makes clear through her overview, these different theories offer different bundles of criteria,

Rubina Raja, Department of Classical Art and Archaeology, Aarhus University, Aarhus, Denmark. E-mail: rubina.raja@cas.au.dk 
thereby creating different ways of defining urban sites. Furthermore, she also clearly shows in which ways geographically focused studies give certain views on what urbanism would have entailed in the past, as well as the fact that different time periods also would have had their unique markers, be it certain technological developments or other intellectual achievements.

Her attentive and knowledgeable overview also raises the question of whether we can in fact compare urbanism(s) at all. Furthermore it disturbingly calls for attention to the question as to whether comparative studies within this field might still be considered useful.

The global and the local perspectives are also brought forward as not always concurring and being comparable, and a thoughtful and critical view on urban theory applied in archaeology makes this contribution a pleasure to read. The author has done her homework and thought hard about it. Nonetheless it remains difficult to transcend the borders which theories, bundles of criteria and methodology force upon one. One size does not fit all and the concept of the city might need to be recapitulated within a completely new framework, which takes us beyond looking for a set of criteria.

Bisserka Gaydarska defines four main points, through which she sees it as possibly being useful to view urbanism and through which the urban-debate might be reformulated.

First, she mentions 'recognition or deconstruction of the uncritical acceptance of "urban" as an analytical category, of the inconsistencies in how the "urban" concept is applied on local and global levels, and the double standard applied to site-based and regional based urban studies'. This is certainly an important point, but pertains very much to a conceptual level beyond which I believe we cannot possibly move. I also would argue that most scholars working with the concept of 'urban' are well aware that this is a complex analytical category which comprises a diversity of elements, and in addition language barriers may hamper how we discuss such concepts.
In her second point, she stays at the level of concepts, moving on to terminology and our embedded understanding of 'urban' or 'city'. She does have a point that language limits imagination and therefore reconstruction. However, we will not be able to rid ourselves of the limits of language. This is her weakest point, where she is knocking on a door already open. No scholar thinks of the 'urban' as a universal term, although some scholars work comparatively across wide geographic spans. Bashing against the primacy of the English language, I fear, is a lost battle and energy is spent better in other ways, although ancient Greek, Latin and several other languages would give us a more nuanced vocabulary to play with.

Certainly we can all agree to her fourth point about the advantages of the integration of big data as a way of making huge advances within the understanding of the 'urban'. Big data are a welcome addition to archaeological research and must be tackled. However, what needs to be addressed is what 'big data' really mean in an archaeological context? How much data is needed for data to be big? And does it tell us anything without comparisons to other sites, which then in turn would reveal different sorts of big data? What I think is interesting to address, and a huge challenge, is how to compare across unequal and incomplete sets of data.

Let me address her third point last, since I am of the opinion that this is the point where she is on to something I would like to hear more about. She begins to enquire into the nature of sites and the nature of the factors which may be hard to pin down but which make sites urban. This is interesting material, but it needs to be pushed further and I urge her to do so in future work. Below I outline only briefly what we in the newly established Centre for Urban Network Evolutions take as our approach to tackling such issues through a 'context first approach' and not in a search for a new list of criteria which define the 'urban'. 
A radical new way of viewing urbanism may be one way of drawing attention in another direction, allowing for a more dynamic view of what it meant and means to be urban. A new research initiative funded by the Danish National Research Foundation Centre for Urban Network Evolutions (UrbNet) based at Aarhus University and co-directed by myself and Søren Sindbæk explores the archaeology and history of urban societies and their networks from the Ancient Mediterranean to medieval Northern Europe and across to the Indian Ocean world. We are an interdisciplinary research initiative, integrating new methods from the natural sciences with contextual cultural studies rooted in the humanities. Approaching urbanism as a network dynamic, we aim to develop a high-definition archaeology to determine how urban networks catalysed societal and environmental expansions and crises in the past.

Through viewing urbanism in a network perspective, we hope to allow for a different perspective on urbanism, urban societies and urban development. Such an approach allows for differentiation which moves beyond bundles of criteria and ticking boxes. Applying such a new approach to urban archaeology may establish a more coherent view of urbanism as a defining expression of civilization. Emerging applications of isotopic, biomolecular and geoarchaeological methods are transforming archaeology's ability to read the scale and pace of events and processes. These methods hold a potential to create a 'high-definition' view of the past, integrating scientific techniques with contextual archaeological and historical approaches. Re-defining urbanism as a network dynamic, such an approach may unleash new forms of data that are able to significantly test, challenge and revise narratives of particular urban sites as well as fundamental assumptions about trajectories, dynamics and causal conditions of urbanism. Through such an approach we hope that over the years we might be able to contribute constructively to nuancing the way in which urban dynamics may be captured and explained. We aim at filling in the gaps, moving from the 'grand narratives' to what we term 'high-definition narratives' and in some case hopefully capture the essence of the moments in time, which made the 'urban'.

Bisserka Gaydarska has written a clever and insightful piece of work, which I hope will be read and cited by many. However, at points she fights a battle which cannot be won and does not need to be won, which is the fight against the 'urban'. Her knowledgeable way of analysing and phrasing arguments would reach much further, if she would stop bashing 'urban' and rather begin to explain phenomenological nuances, which, I rest assured, she can do with her very detailed knowledge. I look forward to the discussions. 